\title{
Integration of Mindfulness and Kawruh Jiwa in Guidance and Counseling Services to Achieve Psychological Well-Being of Students in The Disruption Era
}

\author{
Endang Rifani \\ Pascasarjana Universitas Negeri Semarang \\ endangrifani@students.unnes.ac.id
}

\section{Article History}

accepted 01/11/2019

approved 11/11/2019

published 31/12/2019

\begin{abstract}
The purpose of this paper is to examine the guidance and counseling services by integrating mindfulness and kawruh jiwa as an effort that can be done by school counselors in shaping psychological well-being of students. The era of disruption as an era that has positive and negative impacts and provides opportunities and challenges to influence the psychological condition of students. Psychological well-being becomes important for students in establishing social relations effectively. Mindfulness and kawruh jiwa almost have the same concept that is characterized by acceptance of what it is by not judging, accepting, releasing, conscious, giving way to students to achieve psychological well-being so as to be able to develop their potential more optimally. Kawruh Jiwa as indigenous counseling is considered necessary to be applied to students so that it is not too far apart from the values and understanding of Javanese culture. Concepts and interventions are discussed in this article.
\end{abstract}

Keywords: mindfulness, kawruh jiwa, psychological well-Being, disruption era

\section{Abstrak}

Tujuan dari penulisan ini adalah untuk mengkaji layanan bimbingan dan konseling dengan mengintegrasikan mindfulness dan Kawruh Jiwa sebagai upaya yang dapat dilakukan konselor sekolah dalam membentuk psychological well-being peserta didik. Era disrupsi sebagai era yang memiliki dampak positive dan negative serta memberikan peluang dan tantangan mempengaruhi kondisi psikolgis peserta didik. Psycological well-being menjadi penting bagi peserta didik dalam menjalin relasi sosial secara efektif. Mindfulness dan kawruh jiwa hamper memiliki kesamaan konsep yang dicirikan dengan penerimaan apa adanya dengan tidak menghakimi, menerima, melepaskan, sadar, memberikan jalan bagi peserta didik untuk mencapai psychological well-being sehingga mampu mengembangkan potensi diri secara lebih optimal. Kawruh jiwa sebagai indigenous konseling dirasa perlu untuk diaplikasikan kepada peserta didik agar tidak terlalu jauh terlepas dari nilai-nilai dan pemahaman budaya jawa. Konsep dan intervensi dibahas dalam artikel ini.

Kata kunci: mindfulness, kawruh jiwa, psychological well-being, era disrupsi

Social, Humanities, and Education Studies (SHEs): Conference Series https://jurnal.uns.ac.id/shes

p-ISSN 2620-9284

e-ISSN 2620-9292 


\section{PENDAHULUAN}

Era disrupsi dimana era ini membawa arus kompetisi yang semakin kompleks hingga memberikan tantangan bagi seluruh aspek kehidupan. Pengembangan potensi individu dapat di optimalkan melalui Pendidikan. Begitu pula dengan ranah kesehatan dan kesejahteraan psikologis individu. Menyelamatkan kesehatan mental peserta didik agar dapat mengembangkan potensi yang dimiliki termasuk dalam tanggung jawab sekolah (Visani , Albieri, Ruini, 2014). Perkembangan secara optimal dimana individu dapat memberikan keputusan dan perilaku secara sehat, bertanggung jawab, memiliki keberdayaan serta pola perilaku adaptif dalam menjalani kehidupannya (Permendikbud, No. 111, 2014). Dalam era disrupsi peserta didik dapat menjadi pihak yang menyerap dampak buruk dari adanya perkembangan teknologi. Peserta didik saat ini adalah generasi Z, merupakan generasi yang lahir antara tahun 1995-2010, saat ini berada pada usia remaja hingga menuju dewasa. Masa remaja merupakan masa transisi dalam rentang kehidupan manusia, jembatan dari masa kanak-kanak menuju masa dewasa (Santrock, 2003). Pada rentang usia ini merupakan masa pencarian jati diri hingga mudah menyerap berbagai informasi dan mudah terpengaruhi.

Praktik pelayanan bimbingan dan konseling di sekolah merupakan penentu dari keberdayaan individu dalam menjalani kehidupan yang dihadapi. Ditjen GTIK (2016) menyebutkan bahwa individu berhak mendapatkan kesempatan untuk mengembangkan potensi positif. Psychological well-being penting dalam proses optimalisasi perkembangan potensi peserta didik. Penelitian menujukkan bahwa psychological well-being berpengaruh terhadap kesuksesan akademik (Rüppel, Liersch, \& Walter, 2015). Temuan lain mengungkapkan dukungan sosial bersamaan dengan psychological well-being berpengaruh terhadap prestasi belajar, namun lebih besar pengaruh yang diberikan dukungan sosial dibanding dengan psychological well being (Fitriyani, 2019). Memerlukan intervensi yang bersifat mengedukasi peserta didik untuk mencapai potensi yang dimiliki. (Tadlock-Marlo, 2011) dengan mengitegrasian mindfulness dalam layanan bimbingan dan konseling memberikan pengaruh pada peningkatan performa akademik, mengembangkan sikap sosial, serta mampu mempelajari coping mechanism sebagai upaya meningkatkan kehidupan pribadi yang berkualitas.

Mengitegrasikan mindfulness dan kawruh jiwa dalam layanan bimbingan dan konseling perlu dilakukan oleh konselor sekolah kepada peserta didik untuk mencapai psychological wellbeing sehingga harapannya peserta didik lebih optimal dalam mengembangkan potensi-potensi diri untuk menjalankan peran kehidupan di era disrupsi saat ini. Kawruh jiwa sebagai penerapan indigenous konseling yang berakar dari budaya jawa memberikan jalan pada peserta didik untuk dapat mengenal dan memahami nilai-nilai budaya jawa. (Trisani, Wardani, \& Hana, 2016) intervensi bimbingan kelompok berbasis budaya jawa efektif untuk meningkatkan komunikasi interpersonal siswa SMK di Kabupaten Madiun. (Maulana, Wibowo, \& Tadji, 2014) bimbingan kelompok berbasis budaya jawa dengan teknik permainan efektif dalam meningkatkan interaksi sosial SMP Kota Semarang. Saat ini layanan bimbingan dan konseling sekolah berkiblat pada pengadopsian pemikiran Amerika serikat, dimana dalam prakteknya memiliki beberapa kesenjangan dengan budaya lokal yang ada di Indonesia.maka perlu adanya penerapan dan pembahasan terkait dengan indigenous konseling berbasis budaya yang ada di Indonesia sehingga dapat menjadi alternatif solusi bagi penyelenggara layanan bimbingan dan konseling di sekolah. 


\section{Problematika peserta didik di era disrupsi \\ PEMBAHASAN}

Era disrupsi berkaitan erat dengan perkembangan teknologi digital, dimana banyak sekali dampak positive dan negative yang diberikan. Peserta didik saat ini piawai dalam berselancar di media sosial, namun hal ini dapat memberikan efek buruk bagi kondisi psikologis mereka. Banyak penelitian membahas tentang cyberbullying sebagai efek dari perkembangan teknologi digital. Cyberbullying dapat dikatakan salah satu bentuk degradasi moral. (Donegan, 2012) menyebutkan bahwa cyberbullying merupakan bentuk dari pelampiasaan rasa frustasi pelaku terhadap korban. Dikatakan sebagai aktivitas agresif yang dituangkan melalui perangkat teknologi dan bersifat merugikan terhadap orang lain (Hinduja \& Patchin, 2013). Hasil riset yang dilakukan oleh Polling Indonesia bersinergi dengan Asosiasi Penyelenggara Jasa Internet Indonesia (APJII) dari 5.900 sampel 49\% menyatakan pernah mengalami bullying di media sosial (Kompas.com, 2019). Dampak yang diberikan oleh cyberbullying bagi korban adalah penarikan diri dari lingkungan sosial, rendahnya rasa percaya diri,depresi dan yang terburuk adalah keinginan untuk bunuh diri, disisi lain dampak bagi pelaku adalah mereka lebih mungkin terlibat dalam penggunaan obat-obatan dan perilaku antisosial (Cowie, 2013).

Intensitas penggunaan media sosial memberikan banyak kerugian seperti yang dikatakan oleh (Chen \& Lee, 2013) yang menemukan bahwa facebook sebagai sarana interaksi berkaitan dengan beban kognitif, penurunan harga diri, dan perasaan tertekan. Selain itu kesejahteraan individu dapat mengalami penurunan dengan intensitas penggunaan facebook dari waktu-ke-waktu (Kross et al., 2013). Cyberbullying, pelecehan seksual, dan stalking dapat disalurkan melalui media sosial facebook Kwan\&Skoric (2013) dalam (Fox \& Fox, Jesse; Moreland, 2015). Beberapa kasus tersebut merupakan kasus yang dapat mengancam psychological well-being sehingga memungkinkan menghambat individu dalam pengembangan potensi yang dimiliki. Tantangan yang ada bagi generasi $Z$ di era ini semakin meningkat, seperti tingginya angka perpisahan keluarga, kurangnya koneksi dan interaksi dengan keluarga, hilangnya rasa memiliki terhadap komunitas local mereka, serta keamanan di dunia maya(Noble \& McGrath, 2015).

Tantangan bagi generasi $Z$ di era disrupsi adalah menjadi yang terbaik dari yang terbaik dibutukan untuk mendapatkan posisi kerja yang sesuai dengan standar hidup yang semakin hari semakin kompleks. Sehingga mereka dituntut untuk mengembangkan potensi diri se-apik mungkin agar dapat berkompetisi sesuai dengan tuntutan global. Namun sayangnya generasi $Z$ adalah generasi yang tidak dapat terlepas dari teknologi digital apalagi media social, sehingga berdasarkan kasus yang diuraikan diatas hal ini berdampak pada kesehatan mental mereka. Didukung pula dengan hasil penelitian (Lup, Trub, \& Rosenthal, 2015) bahwa penggunaan media sosial instagam dengan frekuensi berlebih dapat membentuk individu untuk membandingkan diri mereka dan oranglain yang dikenal, lebih buruknya dapat menimbulkan depresi terutama pada dewasa awal. Sangat jelas bahwa semakin kompleksnya problematika yang dialami peserta didik generasi $Z$.

\section{Psychological well-being dalam pengembangan potensi peserta didik}

Ryff (1989) menjelaskan bahwa psychological well-being memiliki enam dimensi yaitu: penerimaan diri, menjalin interkasi secara positif dengan oranglain, otonomi, penguasaan lingkungan, memiliki tujuan hidup, dan pertumbuhan pribadi. 
Individu yang memiliki psychological well-being yang tinggi mampu memberikan kesadarn pribadi dan memaknai keberadaannya, oleh sebab itu individu memiliki kemampuan dalam menyelesaikan tantangan sebagai bentuk aktualisasi diri (Oktavia $T$ \& Nisa, 2018). Keadaan kesejahteraan mental individu merupakan focus dari psychological well-being, kesejahteraan tersebut bersal dari bagaimana individu berhasil menemukan makna hidup, mengalirkan energi emosi secara positif, memiliki pandangan yang psitif terhadp kondisi lingkungan, serta keberdayaan dalam menjalani kehidupan secara lebih baik (Pluess, 2015).

Psychological well-being memberikan efek penting bagi individu untuk mencapai potensi diri dan memenuhi tugas perkembangan secara optimal. hasil penelitian yang dilakukan oleh (Pertiwi \& Nrh, 2019) pada siswa SMP, menujukkan bahwa dengan psychological well-being yang tinggi berhubungan negative pada rasa kecemburuan terhadap saudara kandung (sibling rivalry). Memperkuat bahwa psychological well-being berpengaruh secara positif teradap keberlangsungan hidup manusia. Di era disrupsi yang semakin meningkatkan kompetisi, rasa kebahagiaan dan kebermaknaan hidup menjadi penting dalam menjalani keidupan dan memenuhi tantangan hidup, sebab kebahagiaan dan kebermaknaan hidup disinyalir sebagai sumber kekuatan individu untuk tetap berdaya dalam mengoptimalkan kemampuan. Tidak sedikit studi yang mengatakan bahwa tingkat stress mempengaruhi aspek-aspek kehidupan individu. Jadi pemikirannya begini agar dapat berkembang secara lebih optimal dan potensi terasah kearah yang lebih baik pada setiap bidang masing-masing, individu memerlukan kebahagiaan, kebermaknaan, dan tujuan yang jelas yang mana konsepini ada di psychological well-being.

\section{Konsep mindfulness dan kawruh jiwa}

Akar dari konsep mindfulness adalah tradisi Buddha dan Kontemplasi berfokus pada pemeliharaan perhatian dan kesadaran (Waskito, 2019). (Kabat-Zinn, 1990) menyebutkan bahwa mindfulness berkaitan dengan kesehatan mental dan fisik. Dibandingkan dengan individu dengan mindfulness rendah, individu dengan mindfulness tinggi menujukkan bahwa mereka lebih cenderung bertindak secara etis, lebih mungkin berorientasi pada nilai-nilai, menegakkan standar etika (kepentingan pribadi dari identitas moral, IKM), dan lebih cenderung menggunakan pendekatan berprinsip pada pengambilan keputusan etis (formalisme) (Ruedy \& Schweitzer, 2010). Mindfulness dapat meningkatkan kesadaran orientasi diri dan saat ini, memberikan efek pada peningkatan kesadaran dan penerimaan terhadap apa-apa yang dirasakan saat ini yang berhubungan dengan stress dan mampu meningkatkan rasa belas kasih (Felton, Coates, \& Christopher, 2015). Disebutkan bahwa mindfulness dapat menurunkan fungsi-fungsi negative dan mengembangkan fungsi-fungsi positif (Waskito, 2019). Jika melihat dari berbagai problematika peserta didik saat ini, penulis menduga bahwa konsep mindfulness memiliki efek yang positif bagi perkembangan peserta didik sehingga sangat berpotensi untuk daplikasikan dalam layanan bimbingan dan konseling untuk mencapai psychological wellbeing peserta didik.

Indigenous konseling merupakan konseling yang berakar pada system, nilianilai, kepercayaan, dimana individu itu berada. Kawruh jiwa merupakan konsep yang dapat diintegrasikan dalam bimbingan dan konseling untuk memberdayakan konseli khususnya yang berasal dari Budaya Jawa. Kawruh jiwa memiliki tujuan utama dalam prosesnya yaitu menjadikan individu seseorang yang tegar dalam menjalani dinamika kehidupan. Prinsip dari kawruh jiwa adalah "kini, disini, dan begini", memiliki arti bahwa 
individu mampu menerima keberadaan dan kondisinya saat ini bukan pada apa yang sudah terlewati dan apa yang belum terlewati.

(Marhamah, \& Murtadlo, \& Awalya 2015) menyebutkan bahwa tujuan yang ingin dicapai dari penerapan konseling kawruh jiwa adalah 1) Manusia tanpo tengger artinya manusia dapat benar-benar terlepas dari perihal duniawi, 2) manusia berdaya dalam menghilangkan rasa "aku" kramadangsanya, 3) bahwa kebahagiaan dan kesusahan datang secara bergantian "mulur mungkret", artinya manusia tidak larut dalam bahagia maupun susah, 4) manusia akan mencapai bahagia jika mampu menghilangkan rasa iri "meri", dan kesombongan "pambegan". 5) kebahagiaan dapat dicapai hanya dengan ketika manusia mampu menerima apa adanya "nrimo ing pandhum", 6) manusia dapat menerima hukum alam dan tidak perlu bersusah untuk mengubah hukum alam sebab hanya sia-sia, 7) menjadikan individu mampu menerima kenyataan dengan senang hati.

Kesamaan antara mindfulness dengan kawruh jiwa, sama-sama untuk menerima keadaan saat ini dengan apa adanya, dan mampu menjadikan diri secara penuh dan sadar untuk menrasakan apa-apa yang saat ini terjadi dan dihadapi. Kemudian dari kedua konsep ini akan di integrasikan dalam layanan bimbingan dan konseling bagi peserta didik generasi $Z$ yang memiliki kompleksitas dalam persoalan hdiup yang dihadapi di era disrupsi ini, namun disisi lain memberikan tantangan untuk maju dan berkembang agar dapat berkomeptisi dengan individu lain untuk mencapai perkembangan potensi diri yang optimal kesehatan mental diri kaitannya dengan psychological well-being sangat diperlukan karena mempengaruhi keefektifan individu dalam proses pengembangan diri.

\section{Intervensi mindfulness dan kawruh jiwa untuk mencapai psychological well- being}

Mindfulness didefinisikan sebagai kapasitas psikologis untuk tetap dengan sengaja hadir pada pengalaman seseorang, dengan sikap yang tidak menghakimi atau menerima, menstimulasi keterbukaan dan rasa ingin tahu yang hangat dan ramah (Kabat-Zinn, 2005). Integrasi mindfulness dalam bimbingan dan konseling dapat dicapai dengan layanan dasar, responsive, serta upaya kolaboratif. (Pang \& Ruch, 2019) menjelaskan bahwa mindfulness mampu meningkatkan kesejahteraan, kepuasaan pekerjaan, performa tugas, karena interkoneksi antara mindfulness dengan kekuatan karakter pada psikologi positif. (Dunning et al., 2019) memaparkan intervensi dasar dengan mindfulness merupakan jalan untuk mencapai peningkatan perilaku, kognitif, serta kesehatan mental pada dewasa awal. Untuk mengintegrasikan mindfulness dalam bimbingan dan konseling langkah awal dapat dilakukan dengan berfokus pada pernapasan, berjalan, dan melaksanakan tugas yang bersifat deskriptif (Tadlock-Marlo, 2011). Dalam point ini mindfulness diintegrasikan dalam pelayanan dasar bimbingan dan konseling.

Pelayanan responsif dengan mengintegrasikan mindfulness dan pendekatan konseling yang berbentuk; mindfulnes based stress redaction MBSR (Kabat-Zinn, 1982, 1990), Mindfulnes based cognitive behavior Therapy MBCT (Segal, Teasdale, Williams, \& Gemar, 2002), Dialectical behavioral therapy DBT (Linehan, 1993), Acceptance and Commitment Therapy ACT (Hayes, Strosahl, Wilson, 1999) dalam (Hanley, Abell, Osborn, Roehrig, \& Canto, 2016). Upaya kolaboratif yang dilakukan konselor sekolah dengan piak-pihak yang berpotensi dalam pengemabngan potensi peserta didik seperti stake holder, orangtua, maupun guru mapel. (Waskito, 2019) menjelaskan bahwa Mindfulness dapat diberikan dalam setting kelas dalam proses 
belajar mengajar, pembiasaan dilingkungan sekolah, hal ini dapat membentuk perilaku dan gaya hidup. Melalui penerapan mindfulness dalam lingkup Pendidikan adalah upaya dalam rangka memberdayakan individu dalam mengmbangkan potensi yang dimiliki. Mindfulness sendiri berkaitan erat dengan psychological well-being dimana hal ini jika terintegrasikan dengan baik maka dapat mempermudah jalan bagi peserta didik dalam pengmebangna potensi untuk menghadapi era disrupsi.

Intervensi kawruh jiwa sebagai indigenous konseling memiliki beberapa tahapan sebagaimana dijelaskan dalam Marhamah, murtadlo, \& awalya (2015) beberapa tahapan yang dapat dilakukan dalam pelaksanaan konseling kawruh jiwa adalah sebagai berikut:

1. Meyakinkan peserta didik bahwat; a) sebagai manusia merasakan senang dan susah secara silih berganti; b) manusia dapat membedakan rasa senang dan bahagia sebagaimana dapat membedakan rasa susah dan celaka. Rasa senang dialami ketika "karep" keinginan terpenuhi, dan rasa susah tercipta ketika keinginan tidak terpenuhi. Orientasi susah dan senang ada pada keinginan bukan keadaan. Sikap terhadap keadaan yang menentukan kebahagiaan seseorang; C) Kehidupan adalah takdir yang harus dijalani, individu perlu paham konsep takdir sehingaa akan membentuk keikhlasan dalam menjalani takdir yang terjadi; d) Pengendalian terhadap keinginan dan perlu atau tidak keinginan tersebut dihilangkan; e) Individu berhasil menjiwai konsep "dhewe". Berhasil memisahkan antara diri dan perasaan yang dialami, bahwa senang dan susah sebatas perasaan; f) Bahwa kejayaan, kedudukan, dan kekuasaan bersifat semu; g) Kebahagiaan sejati tercipta ketika individu mampu terlpeas dari sikap egois dan mmperatikan perasaan oranglain; $h$ ) Konselor berperan sebagai fasilitator selebihnya individu yang berusaha untuk mencapai bahagia.

2. Memberdayakan individu untuk memahami konsep bahagia, konselor mengingatkan bahwa; a) untuk hidup bahagia perlu memahami bahwa senang dan susah datang silih berganti; b) mengingat manusia adalah sumber keinginan maka bagaimana individu bisa mengendalikan keinginan. Konselor berperan sebagai pendorong dan pendamping untukk individu mempelajari nilai-nilai kawruh jiwa dan menjadikan orientasi dalam hidupnya. Diperlukan adanya pemaaman yang mendalamtentnag konsep kawruh jiwa lebih baik lagi jika konselor sendiri sudah mengamalkannya dalam kehidupan sehari-hari.

3. Membantu individu memahami, mengerti, serta menjalankan konsep kawruh jiwa. Kawruh jiwa adalah ilmu "laku" tentang falsafa kehidupan jadi bukan hanya tertulis namun perlu dipraktekan dalam kehidupan. Yang perlu dipahami dalam point ini adalah; a) mengaktualisasikan konsep tegar "tatag", individu mampu menerima apapun yang terjadi secara lapang dada; b) mengaktulisasikan "meruhi gagasane dhewe" artinya individu mampu memisahkan antara perasaan dan dirinya; c) mengaktualisasikan bahwa manusia dapat terlepas dari "semat" (kekayaan), "derajat" (kedudukan), "kramat" (kekuasaan); d) mengaktualisasikan pemahaman terkait perubahan kehidupan "mulur mungker" dari bahagia menjadi susah dan sebaliknya; e) mampu memilih baik dan buruk secara sadar; f) memberdayakan peserta didik menjalani hidup dengan enam "sa" yaitu "sasabutuhe" (sebutuhnya), "saperlune" (seperlunya), "sa cukupe" (secukupnya), "sabenere" (sebernarnya), "samestine" (semestinya), "sakpenake" (sepantasnya). 
Konselor berperan sebagai pengingat dan keputusan akhir ada di individu masing-masing. peran konselor sebagai pendamping, sebab kedudukan manusia sama dalam hal ini konsleor bersikap egaliter. Esensi dari kawruh jiwa adalah "pemberdayaan individu untuk belajar menerima proses individu mengenali jati diri, sebagai usaha awal untuk secara sadar mencapai eksistensi". Individu harus siap menerima wejangan dalam proses konseling kawruh jiwa, dan memiliki pandangan kedepan apa yang diinginkan saat ini meskipun sedan dalam kondisi bermasalah, misalnya dengan mentarget "saya harus bahagia". Sejalan dengan konsep psycological well-being bahwa individu secara sadar melakukan tindakan yang efektif bagi dirinya. Kawruh jiwa dapat diimplementasikan dalam bimbingan kelompok, konseling kelompok, dan konseling individu.

Indigenous konseling berbasis nilai-nilai jawa perlu diimplementasikan dalam proses pemberian layanan bimbingan dan konseling, terutama pada peserta didik yang berbudaya jawa, selain untuk melestarikan dan membentuk karakter bangsa melalui upaya ini diharapkan peserta didik lebih memahami akan nilai-nilai budaya Indonesia. Intervensi bimbingan kelompok berbasis nilai karakter local jawa efektif untuk meningkatkan self-awareness peserta didik SMP (Dewi, 2016). Mengingat arus globalisasi telah mengancam lunturnya nilai-nilai karakter bangsa. Mengintegrasikan pendekatan atau teknik konseling yang berasal dari luar dengan budaya jawa memiliki potensi untuk direalisasikan oleh konselor sekolah, disamping untuk penguasaan teori dan pendekatan konseling juga membentuk konselor yang sadar akan budaya.

\section{SIMPULAN}

Psychological well-being memiliki peranan kursial dalam keberdayaan individu untuk mengotpimalkan potensi yang dimiliki, untuk mencapai psychological well-being layanan bimbingan dan konseling dengan mindfulness dapat diiplementasikan kepada peserta didik di era disrupsi yang mana banyak mengalami probelamtika kehidupan, seperi mereduksi stress akademik, dan agresifitas dalam berperilaku, disamping itu konselor perlu untuk mengimplementasikan Indigenous konseling yang berpegang pada nilai-nilai dan norma budaya dimana individu berada, melalui indigenous konseling dengan kawruh jiwa konselor dapat menanamkan nilai-nilai yang terkandung pada peserta didik saat ini agar dapat mereduksi ampak negative yang disebabkan oleh era disrupsi sebagai pergeseran budaya, dan menanamkan perilaku sesuai dengan falsafah yang terkandung untuk mencapai psychological well-being, konsepnya adalah bagaimana individu dapat merasakan kehadiran saat ini dan disini, mengargai sesama dan tidak egois, konsep ini memiliki kesamaan dengan psychological wellbeing sehingga penulis mengkonsepkan baha untuk mencapai psychological wellbeing konselor dapat mengintegrasikan kawruh jiwa dalam bimbingan dan konseling.

\section{DAFTAR PUSTAKA}

Chen, W., \& Lee, K. H. (2013). Sharing, liking, commenting, and distressed? the pathway between Facebook interaction and psychological distress. Cyberpsychology, Behavior, and Social Networking, 16(10), 728-734. https://doi.org/10.1089/cyber.2012.0272

Cowie, H. (2013). Cyberbullying and its impact on young people's emotional health and well-being. Psychiatrist, 37(5), 167-170. https://doi.org/10.1192/pb.bp.112.040840

Dalila Visani , Elisa Albieri, and C. R. (2014). School Programs for the Prevention of Mental Health Problems and the Promotion of Psychological Well-being in Children. Increasing Psychological Well-Being in Clinical and Educational Settings. Cross-Cultural Advancements in Positive Psychology, 8(October), 5774. https://doi.org/10.1007/978-94-017-8669-0 
Dewi, N. K. (2016). Pengembangan Model Bimbingan Kelompok Berbasis Nilai Karakter Lokal Jawa Untuk Meningkatkan Kesadaran Diri (Self Awareness) Siswa. Counsellia: Jurnal Bimbingan Dan Konseling, 3(1). https://doi.org/10.25273/counsellia.v3i1.231

Donegan, R. (2012). Bullying and Cyberbullying: History, Statistics, Law, Prevention and Analysis. The Elon Journal of Undergraduate Research in Communications, 3(1), 33-42.

Dunning, D. L., Griffiths, K., Kuyken, W., Crane, C., Foulkes, L., Parker, J., \& Dalgleish, T. (2019). Research Review: The effects of mindfulness-based interventions on cognition and mental health in children and adolescents - a meta-analysis of randomized controlled trials. Journal of Child Psychology and Psychiatry and Allied Disciplines, 60(3), 244-258. https://doi.org/10.1111/jcpp.12980

Felton, T. M., Coates, L., \& Christopher, J. C. (2015). Impact of Mindfulness Training on Counseling Students' Perceptions of Stress. Mindfulness, 6(2), 159-169. https://doi.org/10.1007/s12671-013-0240-8

Fitriyani, N., \& Belajar, P. (2019). Pengaruh Dukungan Sosial dan Psychological Well Being terhadap Prestasi Belajar Santri Kelas X ( Studi Kasus di MBS Sleman dan Ibnul Qoyyim Putri ). X(1).

Fox, J., \& Fox, Jesse; Moreland, J. (2015). The dark side of social networking sites: An exploration of the relational and psychological stressors associated with Facebook use and affordances - 1-s2.0-S0747563214007018-main.pdf. Computers in Human Behavior, 45, 168-176. Retrieved from http://ac.elscdn.com.proxy.library.msstate.edu/S0747563214007018/1-s2.0S0747563214007018-main.pdf?_tid=e04ac370-485d-11e5-a34400000aabOf27\&acdnat $=1440200553 \_852376365$ fced428769532e7bdc810ef

Hanley, A. W., Abell, N., Osborn, D. S., Roehrig, A. D., \& Canto, A. I. (2016). Mind the Gaps: Are Conclusions about Mindfulness Entirely Conclusive? Journal of Counseling and Development, 94(1), 103-113. https://doi.org/10.1002/jcad.12066

Hinduja, S., \& Patchin, J. W. (2013). Social Influences on Cyberbullying Behaviors Among Middle and High School Students. Journal of Youth and Adolescence, 42(5), 711-722. https://doi.org/10.1007/s10964-012-9902-4

Kabat-Zinn, J. (1982). Mindfulness_chronic_pains_kabatzinn_mbsr_1982.pdf (pp. 3347). pp. 33-47.

Kabat-Zinn, J. (1990). Full Catastrophe Living - Kabat-Zinn.pdf (pp. 59-72). pp. 59-72.

Kross, E., Verduyn, P., Demiralp, E., Park, J., Lee, D. S., Lin, N., ... Ybarra, O. (2013). Facebook use predicts declines in subjective well-being in young adults. Forschende Komplementarmedizin, 20(5), 391-392. https://doi.org/10.1371/journal.pone.0069841

Lup, K., Trub, L., \& Rosenthal, L. (2015). Instagram \#Instasad?: Exploring Associations Among Instagram Use, Depressive Symptoms, Negative Social Comparison, and Strangers Followed. Cyberpsychology, Behavior, and Social Networking, 18(5), 247-252. https://doi.org/10.1089/cyber.2014.0560

Maulana, Wibowo, \& Tadjri. (2014). Model Bimbingan Kelompok Berbasis Budaya Jawa Dengan Teknik Permainan Untuk Meningkatkan Interaksi Sosial Siswa Smp Kota Semarang. Jurnal Bimbingan Konseling, 3(2).

Noble, T., \& McGrath, H. (2015). PROSPER: A New Framework for Positive Education. Psychology of Well-Being, 5(1). https://doi.org/10.1186/s13612-015-0030-2

Oktavia T, L., \& Nisa, A. N. (2018). Penguatan Pendidikan Karakter melalui Pelaksanaan Bimbingan dan Konseling Berbasis pada Psychological Well Being Siswa. Satya Widya, 34(1), 31-38. https://doi.org/10.24246/j.sw.2018.v34.i1.p3138

Pang, D., \& Ruch, W. (2019). Fusing character strengths and mindfulness 
SHEs: Conference Series 2 (2) (2019) 15 - 23

interventions: Benefits for job satisfaction and performance. Journal of Occupational Health Psychology, 24(1), 150-162. https://doi.org/10.1037/ocp0000144

Pertiwi, R. G., \& Nrh, F. (2019). Hubungan Antara Sibling Rivalry Dengan Psychological Well-Being Pada Siswa Kelas Vii Smp Negeri 12 Semarang. Empati, 7(4), 143-151.

Pluess, M. (2015). Individual Differences in Environmental Sensitivity. Child Development Perspectives, 9(3), 138-143. https://doi.org/10.1111/cdep.12120

Ruedy, N. E., \& Schweitzer, M. E. (2010). In the Moment: The Effect of Mindfulness on Ethical Decision Making. Journal of Business Ethics, 95(SUPPL. 1), 73-87. https://doi.org/10.1007/s10551-011-0796-y

Rüppel, F., Liersch, S., \& Walter, U. (2015). The influence of psychological well-being on academic success. Journal of Public Health (Germany), 23(1), 15-24. https://doi.org/10.1007/s10389-015-0654-y

Ryff, C. D. (1989). Happiness is everything, or is it? Explorations on the meaning of psychological well-being. Journal of Personality and Social Psychology, 57(6), 1069-1081. https://doi.org/10.1037/0022-3514.57.6.1069

Segal, Z. V., Teasdale, J. D., Williams, J. M., \& Gemar, M. C. (2002). The mindfulnessbased cognitive therapy adherence scale: Inter-rater reliability, adherence to protocol and treatment distinctiveness. Clinical Psychology and Psychotherapy, 9(2), 131-138. https://doi.org/10.1002/cpp.320

Suryomentaram, A., Kawruh, D., Marhamah, U., \& Murtadlo, A. (2015). Indigenous Konseling ( Studi Pemikiran Kearifan Lokal Ki Ageng Suryomentaram Dalam Kawruh Jiwa ). Jurnal Bimbingan Konseling (Semarang), 4(2), 100-108.

Tadlock-Marlo, R. L. (2011). Making minds matter: Infusing mindfulness into school counseling. Journal of Creativity in Mental Health, 6(3), 220-233. https://doi.org/10.1080/15401383.2011.605079

Trisani, Wardani, \& Hana. (2016). Efektifitas Bimbingan Kelompok Berbasis Budaya Jawa Untuk Meningkatkan Komunikasi Interpersonal Siswa Smk Pgri Wonoasr. Conselia Jurnal Bimbingan Dan Konseling, 6(1), 54-70.

Waskito, P. (2019). Mindfulness dalam Layanan Bimbingan dan Konseling bagi Peserta Didik Remaja di Sekolah Menengah Pertama. (April), 27-29. 